\title{
Métodos para a Avaliação de Riscos Laborais: Método Simplificado, MARAT (Metodologia de Avaliação de Riscos e Acidentes de Trabalho) ou NTP330
}

Santos M, Almeida A, Lopes C, Oliveira T. Métodos para a Avaliação de Riscos Laborais: Método Simplificado, MARAT (Metodologia de Avaliação de Riscos e Acidentes de Trabalho) ou NTP330. Revista Portuguesa de Saúde Ocupacional on line. 2019, volume 6, 1-5. DOI: 10.31252/RPSO.18.02.2019

IIPO DE ARTIGO: Artigos da Equipa Técnica

Autores: Santos M(1), Almeida A(2), Lopes C(3), Oliveira T(4).

Trata-se de um método elaborado pelo Instituto Nacional de Seguridad e Higiene en el Trabajo (INSHT), que permite hierarquizar os riscos, possibilitando uma ordem na intervenção.

Aqui $R=f(P \times C)$, em que $R$ é o conjunto de danos esperados por unidade de tempo, $P$ a probabilidade de ocorrência ou nível de probabilidade (NP) e C as consequências ou nível de consequências (NC). Assim, $R=N P \times N C$ e $N P=N E \times N D$, em que NE é o nível de Exposição e ND o nível de Deficiência.

Este método inicia-se pela definição do posto de trabalho a estudar e colheita de dados sobre o mesmo (legislação, manuais de máquinas, fichas de segurança, dados estatísticos, exposição dos trabalhadores) e prossegue com a elaboração de uma lista de verificação associada aos riscos a analisar.

No final obtém-se um Nível de Intervenção e analisam-se os resultados. Neste método não se usam valores reais, mas apenas os seus níveis. O preenchimento deverá ocorrer no local de trabalho.

Nos quadros 1 e 2 podem ser consultados os significados atribuídos aos diversos Níveis de Exposição e de Deficiência.

Quadro 1: Significado dos Níveis de Exposição

Nível de NE Significado
exposição

Contínua (EC) $\quad 4 \quad$ Várias vezes ao dia com períodos prolongados 
Frequente (EF) 3 Várias vezes ao dia, mas com intervalos longos sem exposição

Ocasional (EO) 2 Alguma vez ao dia e por períodos curtos

Esporádica (EE) 1 Irregularmente

Quadro 2: Significado dos Níveis de Deficiência

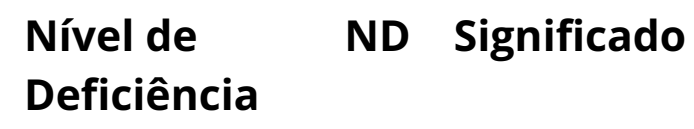

Muito

10 Detetados riscos significativos, possível origem de

deficiente acidentes, medidas preventivas ineficazes

(MD)

Deficiente 6 Fator de risco que requer correção; a eficácia das medidas

(D) preventivas decresce acentuadamente

Melhorável 2 Riscos de menor importância; eficácia das medidas

(M) preventivas não foi afetada

Aceitável (A) - Nenhuma anomalia encontrada; risco controlado; sem valorização

No quadro 3 está registada a conjugação entre os Níveis de Exposição e Deficiência.

Quadro 3: Conjugação entre os Níveis de Exposição e Deficiência

Nível de exposição (NE)

\begin{tabular}{llllll}
\hline & & 4 & 3 & 2 & 1 \\
\hline $\begin{array}{l}\text { Níveis de deficiência } \\
\text { (NP) }\end{array}$ & 10 & MA- 40 & MA- 30 & A-20 & A-10 \\
& 6 & MA- 24 & A-18 & A-12 & A-6 \\
\hline 2 & M- 8 & M- 6 & B- 4 & B- 2
\end{tabular}

No quadro 4 podem ser encontrados os significados dos diversos Níveis de Probabilidade.

Quadro 4: Significado dos Níveis de Probabilidade

Nível de NP Significado
probabilidade


Muito alta 24 Situação deficitária com exposição continuada ou muito

(MA) a deficitária com exposição frequente; acidentes ocorrem

40 com frequência

Alta (A) $\quad 10$ Situação deficitária com exposição frequente ou ocasional

a ou muito deficiente com exposição ocasional/ esporádica;

20 possibilidade alta de acidentes

Média (M) $\quad 6$ a Situação deficitária com exposição esporádica ou

8 melhorável com exposição continuada ou frequente; acidentes ocasionais

Baixa (B) $\quad 2$ a Situação melhorável com exposição ocasional ou

4 esporádica; acidentes improváveis, mas não impossíveis

Por sua vez, no quadro 5 podem ser observados os significados dos Níveis de Consequências.

Quadro 5: Significado dos Níveis de Consequências

\section{Significado}

Nível de NC Danos pessoais Danos materiais
consequências

Mortal ou 100 Um morto pelo menos Destruição total do sistema catastrófica

(M)

$\begin{array}{lll}\begin{array}{l}\text { Muito grave } \\ \text { (MG) }\end{array} & \begin{array}{l}\text { Lesões graves que } \\ \text { podem ser irreparáveis }\end{array} & \begin{array}{l}\text { Destruição parcial do sistema } \\ \text { (recuperação custosa) }\end{array}\end{array}$

$\begin{array}{lll}\text { Grave (G) } 25 & \begin{array}{l}\text { Lesões com incapacidade } \\ \text { laborais temporárias }\end{array} & \begin{array}{l}\text { Paragem obrigatória do } \\ \text { processo para efetuar a } \\ \text { reparação }\end{array}\end{array}$

Leve (L) $\quad 10$ Pequenas lesões que não Reparável sem necessitar de requerem hospitalização paragem

Relembra-se que o NR = NP x NC. No quadro 6 é possível analisar a conjugação entre os Níveis de Probabilidades e de Consequências.

Quadro 6: Conjugação entre os Níveis de Probabilidade e de Consequências 


\begin{tabular}{|c|c|c|c|c|c|}
\hline & & 40- 24 & 20- 10 & 8- 6 & 4- 2 \\
\hline \multirow[t]{4}{*}{$\begin{array}{l}\text { Nível de Consequências } \\
\text { (NC) }\end{array}$} & 100 & $\begin{array}{l}1 \\
4000- \\
2400\end{array}$ & $\begin{array}{l}\text { I } \\
2000- \\
1200\end{array}$ & $800-600$ & $\begin{array}{l}\text { II } \\
400- \\
200\end{array}$ \\
\hline & 60 & $\begin{array}{l}\text { I } \\
2400- \\
1440\end{array}$ & $\begin{array}{l}\text { I } \\
1200-600\end{array}$ & $\begin{array}{l}\text { II } \\
480- \\
360\end{array}$ & $\begin{array}{l}\text { II } 240 \\
\text { III } 120\end{array}$ \\
\hline & 25 & $\begin{array}{l}\text { I } \\
1000-600\end{array}$ & $\begin{array}{l}\text { II } \\
500-250\end{array}$ & $\begin{array}{l}\text { II } \\
200- \\
150\end{array}$ & $\begin{array}{l}\text { III } \\
100-50\end{array}$ \\
\hline & 10 & $\begin{array}{l}\text { I } \\
400-240\end{array}$ & $\begin{array}{l}\text { II } 200 \\
\text { III } 100\end{array}$ & $\begin{array}{l}\text { III } \\
80-60\end{array}$ & $\begin{array}{l}\text { III } 40 \\
\text { IV } 20\end{array}$ \\
\hline
\end{tabular}

Por fim, no quadro 7, estão estratificados os Níveis de Intervenção, em função dos Níveis de Risco.

Quadro 7: Significado dos Níveis de Intervenção

\section{Nível de NR Significado \\ Intervenção}

1 4000- Situação crítica; correção urgente 6000

2 150- Corrigir e adotar medidas de controlo

500

3 40- Melhorar se possível; é conveniente justificar a

120 intervenção e a sua rentabilidade

$420 \quad$ Não é necessário intervir, salvo se outra análise mais exigente o justificar

Perante valores equivalentes será preferível intervir em sistemas em que o custo for menor e se atinja um maior número de funcionários. Contudo, por sua vez, não se deve ignorar a valorização que os trabalhadores poderão dar a alguns problemas.

Para finalizar, no quadro 8 é fornecido um exemplo de tabela de registo. 
Perigos Dano MD NE NP NC NR NI Ações de controlo propostas

\section{BIBLIOGRAFIA GERAL}

(usada na elaboração de todos os artigos relativos a métodos para avaliação dos riscos)

1-Pedro R. Métodos de Avaliação e Identificação de Riscos nos locais de Trabalho. Tecnometal. 2006, 167, 1-8.

2- Mendonça A. Métodos de Avaliação de Riscos- contributo para a sua aplicabilidade no setor da Construção Civil. Relatório de Atividade Profissional para a obtenção do Grau de Mestre em Engenharia do Ambiente. Faculdade de Ciência e Tecnologia, Universidade do Algarve. 2013, 1-225.

3-Batista J. Adaptação de Métodos Matriciais para a Avaliação de Riscos Profissionais. Safemed. 2016, 1-22.

\section{(1)Mónica Santos}

Licenciada em Medicina; Especialista em Medicina Geral e Familiar; Mestre em Ciências do Desporto; Especialista em Medicina do Trabalho e Doutoranda em Segurança e Saúde Ocupacionais, na Faculdade de Engenharia da Universidade do Porto. Presentemente a exercer nas empresas Medicisforma, Servinecra e Securilabor; Diretora Clínica das empresas Quercia e Gliese; Diretora da Revista Portuguesa de Saúde Ocupacional on line. Endereços para correspondência: Rua Agostinho Fernando Oliveira Guedes, 42, 4420-009 Gondomar. E-mail: s_monica_santos@hotmail.com.

\section{(2)Armando Almeida}

Doutorado em Enfermagem; Mestre em Enfermagem Avançada; Especialista em Enfermagem Comunitária; Pós-graduado em Supervisão Clínica e em Sistemas de Informação em Enfermagem; Docente na Escola de Enfermagem (Porto), Instituto da Ciências da Saúde da Universidade Católica Portuguesa; Diretor Adjunto da Revista Portuguesa de Saúde Ocupacional on line. 4420-009 Gondomar. E-mail: aalmeida@porto.ucp.pt.

\section{(3)Catarina Lopes}

Licenciada em Enfermagem, desde 2010, pela Escola Superior de Saúde Vale do Ave. A exercer funções na área da Saúde Ocupacional desde 2011 como Enfermeira do trabalho autorizada pela Direção Geral de Saúde, tendo sido a responsável pela 
gestão do departamento de Saúde Ocupacional de uma empresa prestadora de serviços externos durante 7 anos. Atualmente acumula funções como Enfermeira de Saúde Ocupacional e exerce como Enfermeira Generalista na SNS24. Encontrase a frequentar o curso Técnico Superior de Segurança do Trabalho. 4715-028. Braga. E-mail: catarinafflopes@gmail.com

\section{(4)Tiago Oliveira}

Licenciado em Enfermagem pela Universidade Católica Portuguesa. Frequenta o curso de Técnico Superior de Segurança no Trabalho. Atualmente exerce a tempo inteiro como Enfermeiro do Trabalho. No âmbito desportivo desenvolveu competências no exercício de funções de Coordenador Comercial na empresa Academia Fitness Center, assim como de Enfermeiro pelo clube de futebol União Desportiva Valonguense. 4435-718 Baguim do Monte. E-mail: tiago_sc16@hotmail.com. 